\title{
CORTE / TRIBUNAL CONSTITUCIONAL INTERNACIONAL Nota de Abertura
}

Os filósofos britânicos John Locke e David Hume são por vezes apontados como tendo dado a solução final para os clamores dos reiteradamente injustiçados: depois de esgotados os recursos nos respetivos países, subidas as petições às Cortes das Cortes, a solução que restaria não poderia deixar de ser um recurso para o céu. Pequena consolação neste mundo sublunar.

Com efeito, como no filme de Ersnst Lubitsch (que no Brasil se chamou $O$ Diabo disse Não), diríamos que $O$ Céu pode esperar (USA, 1943). Podemos na verdade esperar pelo recurso para o céu. O recurso do juízo final ou mesmo particular, ou qualquer outra modalidade de dar o seu a seu dono (suum cuique tribuere) fora do nosso tempo e espaço terrenos é de um foro que ultrapassa o jurídico. Mas não podemos esperar indefinidamente por recursos para entidades na Terra. Nem tolerar que a Justiça seja denegada, designadamente por interesses pessoais, corporativos ou políticos.

Os juristas (e com ele todas as Pessoas de boa vontade) não podem conformarse com a essa denegação da justiça, a fraude, a corrupção, os atentados às próprias leis que nos Estados se fazem (desde logo à lei das leis, as suas Constituições) e tampouco com o desprezo a que alguns votam os seus tratados internacionais, dentro e fora dos seus países.

A ideia de uma Corte Constitucional Internacional, surgida precisamente do fechamento do sistema interno da Tunísia (gizada em 1999 pelo Dr. Mocef Mazurki, quando ainda na oposição), como via para a sua superação, tem vindo a ganhar terreno ao nível internacional, sobretudo académico.

Em 17 junho de 2015, em sessão sob a presidência do Decano Yadh ben Achour, tivemos a honra de apresentar a proposta de uma Declaração no Colóquio que marcou uma nova fase nos trabalhos em prol da nova Corte, que necessariamente terão de passar, no futuro próximo, pelo envolvimento diplomático e político. Julgamos importante publicitá-la aqui:

\section{DECLARATION DE RABAT SUR LA COUR CONSTITUTIONNELLE INTERNATIONALE}

Réunis à Rabat, les 16 et 17 juin 2015, à l'occasion du colloque international sur "Une Cour Constitutionelle internationale au service du droit démocratique et du droit constitutionnel", organisé par l'Association pour la recherche sur la transition démocratique, en collaboration avec la Faculté de Sciences Juridiques, Economiques et Sociales de l'Université Mohamed V, le CIRID de l'Université Laurentienne, et en partenariat avec la Fondation Konrad Adenauer, des chercheurs, professeurs, académiciens, étudiants, experts de différents continents,

considérant: 
1. La nécessité de prendre en considération les droits, les libertés et leurs garanties, au niveau global, aussi bien que les engagements des Etats, pour la cause de la paix et de la dignité humaine ;

2. Le développement des études et recherches ainsi que l'intérêt de l'opinion publique mondiale pour l'idée de création d'une cour constitutionnelle internationale ;

3. L'importance de la coordination des efforts et des volontés autour de ce projet innovant.

Tout en restant ouverts au débat démocratique et avec la plus complète ouverture d'esprit, affirment :

1. Leur conviction que la reconnaissance d'une normativité constitutionnelle internationale, mondiale ou globale et des principes d'une constitution matérielle, qui existent déjà, n'impliquent nullement l'existence d'un Etat planétaire ni une constitution mondiale formelle.

2. Leur croyance qu'une Cour constitutionnelle internationale constituera un pas décisif pour l'universalisation et l'effectivité de l'Etat de droit, de la démocratie et des droits de l'Homme.

3. Leur intention de travailler pour l'élaboration d'un projet d'avenir, réfléchi et réaliste qui puisse évoluer vers des solutions acceptables et consensuelles

Décidons, en conséquence, de créer un collectif pour la Cour Constitutionnelle Internationale, qui pourrait avoir des sections nationales et / ou régionales, en vue de poursuivre la réflexion et la finalisation du projet.

No momento em que, sob o impulso da Prof. Asma Grachen, do Prof. Henri Pallard e tantos outros, se trabalha para a concretização desse coletivo internacional em rede, para que aponta a Declaração, o convite da International Studies on Law and Education e da Notandum para ser editor de vários números sobre a temática não poderia vir mais a propósito. Deve-se ao rasgo, excecional visão e amizade do Prof. Dr. Jean Lauand, seu grande timoneiro, a quem penhoradamente agradecemos. E não é por acaso que a publicação é luso-brasileira, assinalando um especial empenhamento da Língua Portuguesa neste projeto universal... Foi com essa certeza que, já em 2014, escolhemos pessoalmente São Paulo para sedear esta missão ao serviço da causa, para que nos foi concedida licença de serviço da nossa Cátedra na Universidade do Porto.

Estas revistas representam uma das primeiras publicações sistemáticas sobre a temática, e estamos certo de que virão a ficar futuramente como marcos importantes para o estudo de uma instituição que se pretende venha a mudar o panorama internacional do Direito e da Justiça.

Elas só são obviamente possíveis pelo contributo empenhado de tão prestigiados colaboradores, a quem agradecemos. Optamos por não fazer aceção de pessoas, tendo convidado personalidades favoráveis, outras mais reticentes, outras mesmo desfavoráveis ao Projeto. Será do diálogo entre todos que poderemos melhor pensar o futuro do Direito.

São Paulo, 3 de outubro de 2015 